Another guiding principle is that science should be made intelligible and enjoyable, even in the work of the public examinations. Experimental work is a conspicuous part of the Nuffield courses. Many local authorities have helped to give the courses a fair trial by spending soveral hundreds of pounds a school on new scientific equipment.

Alternative O-levol examinations for children using Nuffield courses in physics, chemistry and biology are to be provided by the public examinations in the years ahead, so that children engaged in the testing of new courses will not be hampered. A hundred titles in the first printing of about three million books will appear in spring
1966 and, in addition, there are films, film loops and other special itoms of equipment developed during the programme, and other visual aids.

The future of the $\mathrm{O}$-level courses is said in the report to depend on tho extent to which practising teachers will be helped to make the best use of the new methods. No charitable organization can be responsible for the work in the future, and the Department of Education and the local education authorities will have to give major support. The report outlines future developments, including a project to teach general science in the 11-13 age range.

W. L. SUMNER

\title{
ANTIMICROBIAL AGENTS AND CHEMOTHERAPY
}

$\mathrm{V}$ ARIOUS aspects of antimicrobial agents, infectious diseases, microbiology, and chemotherapy were discussed in the 162 papers presented at the fourth Interscience Conference on Antimicrobial Agents and Chemotherapy. This meeting was held in New York during October 26-28, 1964, under tho sponsorship of the American Society for Microbiology and organized with the co-oporation of the Infectious Diseases Society of America. Dr. N. Bohonos (Lederle Laboratories) was chairman of the conference. 1,045 scientists attended this meeting, including representatives from eighteen countries in all.

The three-day conference opened with an address by Dr. M. Finland (retiring president of the Infectious Diseuses Society) on problems in the clinical investigation of new drugs. The role of the U.S. Food and Drug Administration and other rogulatory agencies was reviewed, and the necessity of allowing the investigator to exercise some initiative and responsibility was mentioned. The John Scott Award for meritorious seientific achievement was presented at this session by the City of Philadelphia (Pennsylvania) to Prof. J. C. Sheehan (Massachusetts Institute of 'Technology) for his research loading to tho preparation of the 'semi-synthetic penicillins'.

Among the features of the 1964 meeting wore four symposia. Prof. M. Hamburger chaired the first, which dealt with "Penicillins and Cephalosporins" and included reviews of the clinical status of cephalothin (by W. M. M. Kirby), ampicillin (by S. Ross), oxacillin and methicillin (by H. Simon), and nafcillin (by C. M. Martin). P. B. Bunn described his experience with penicillin allergy and emphasized the apparent lack of strong sensitivity to ampicillin of patients allergic to benzylpenicillin (penicillin $G)$. It was obvious that some of these newor semi-synthetic penicillins were as clinically useful in treatment of certain Gram-negative infections as some of the other antibiotics, for example, chloramphenicol, polymyxin, and colistin. However, as Prof. Simon pointed out, we do not as yet have a 'panaceamycin' for all infections. M. R. Pollock, (National Institute for Medical Research, London) summarized his investigations of the $\beta$-lactamasos of bacteria. These enzymes, which inactivate both penicillins and cephalosporins under laboratory conditions, may not be entirely responsible for the penicillin resistance noted in certain bacterial cultures.

Dr. H. C. Reilly (Sloan Kettering Institute) presided over a symposium on "Antinooplastic Antibiotics". S. A. Schepartz reviewed the programme of the Cancer Chemotherapy National Screening Center, in which searches are being made for anti-neoplastic antibiotics from fermentation processes. Thirty materials (isolated from more than 115,000 'crude' broths screened) have been considered for clinical evaluation, but none has shown 'great promiso'. An investigation of the incidence of anti-neoplastic activity among antibiotics that act as inducers of lysogenio bacteria was discussed by $\mathrm{K}$. F. Price (Bristol Laboratories), who found a high correlation between anti-neoplastic activity and induction of lambda phage in $E$. coli W1709. J. J. Fox (Sloan Kettering Institute) reported that gougerotin contains sarcosyl-D-serine in acyl-amino linkage to 4-amino-4-deoxy-hexuronic acid amide, and concluded that the structure proposed earlier for this antibiotic was in error. He pointed out that all known pyrimidine nucleoside antibiotics (elaborated by Streptomyces species) contain cytosine and 4-amino-hexose moieties. A. Bloch and C. A. Nichol (Roswell Park Memorial Institute) commented on the nucleoside antibiotics related to adenosine with special reference to their effects on adenosine phosphorylase, deaminase, and kinase. R. D. Sullivan (Lahey Clinic Foundation, Boston) pointed out that doses $2-2.5$ times as great as those tolerated by single daily injection were woll tolerated by prolonged intravenous infusion of actinomycin $D$, streptonigrin, and mitomycin $C$, and went on to review recent progress in the use of these antibiotics in cancer chomotherapy.

"The Future of Antiviral Drugs" was the subject of a session convened by E. C. Herrmann, jun. (The Mayo Clinic). F. M. Schabel (Southern Research Institute) and I. S. Johnson (Eli Lilly and Co.) discussed the theoretical basis for examining antiviral chemotherapy and problems in the detection of antiviral antibiotics. The successes in viral troatment following the use of 5 -iodo- $2^{\prime}$-deoxyuridine, cytosine, and 5 -azaorotic acid were reviewed by P.Calabresi (Yale University); and R. L. Thompson (National Institutes of Health, Bethesda) summarized the tests with $N$ methylisatin- $\beta$-thiosemicarbazone and other thiosemicarbazones. The promising laboratory and clinical results with l-adamantanamine hydrochloride were reviewed by C. E. Hoffman (E. I. DuPont de Nemours and Co.).

"The Usefulness of Synthetic Antimicrobials" was the subject of a symposium chaired by Dr. D. Lehr (New York Medical College). Dr. J. Alban (Stanford University), E. H. Kass (Harvard University), J. P. Colmore (Oklahoma Medical Center), and D. F. MeDonald (University of Rochester) gave information on the present status of the sulphonamides, nitrofurantoins, and nalidixic acid.

Among the new antibiotics mentioned at the Conference were:

(l) The S-ethyl homologue of lincomycin and $N$ demethyl analogue of lincomycin formed by adding DL-ethionine and $\alpha$-methylthiolincosamide, respectively, to lincomycin-producing fermentations according to Argoudelis et al. (The Upjohn Co.). (2) Everninomicin, a new antibiotic complex derived from Micromonospora carbonacea which inhibits Gram-positive bacteria and PPLO, as shown by Weinstein et al. (Schering Corporation). (3) Almarcetin, a new polypeptide antibiotic which may be useful against phytopathogens, according to Bachler et al. (Northern Regional Research Laboratory, U.S. Department of Agriculture). (4) Monicamycin, an acidic heptaene antifungal agent isolated by Gupta (Regional Research Laboratory, Jammu-Tawi, India). (5) Rubiflavin, a toxic anti-tumour antibiotic described by Aszalos et al. (Squibb Institute for Medical Research). (6) $U-13714$, a 
toxic antiviral agent isolated by Vavra et al. (The Upjohn Co.) from Streptomyces canarius. (7) $L L$-AP191, a xanthomycin-type antibiotic inhibiting both Grampositive and Gram-negative bacteria according to $\mathrm{H}$. A. Whaley et al. (Lederle Laboratories). (8) $L L-A 1471 E$, a macrolide antibiotic inhibiting Gram-positive bacteria, reported by M. P. Kunstmann et al. (Lederle Laboratories). (9) U-11092, an antibiotic inhibiting Gram-positive bacteria in vivo when given either per os or subcutaneously, according to B. K. Bhuyan et al. (The Upjohn Co.). (10) Enteromycin (seligocidin) from a streptozotocin-producing fermentation, as reported by R. R. Herr et al. (The Upjohn Co.). (11) Enteromycin carboxamide isolated by S. DeVoe et al. (Lederle Laboratories) from a streptomycete fermentation.

A wide variety of topics were discussed in the sessions concerned with clinical problems and treatment in humans: (1) Animal infections examinations which were pertinent to understanding host resistance and drug action, which included: pneumococcal infections in splenectomized monkeys; prophylaxis of aerogenic Rocky Mountain spotted fever in monkeys; experimental histoplasmosis capsulation endocarditis; coxsackie $A .9$ infection in adult mice treated with steroids and in mice with forced exercise; penicillin toxicity in guinea-pigs as related to changes in microbial flora; and renal infection with enterococcal protoplasts (in rats). (2) Clinical investigations concerned several chronic conditions, which included: fungal diseases in reticuloendothelial malignancies; infection in volunteers with penicillin-resistant gonococci; staphylococcal carriers; chronic bronchitis and pulmonary disease; retreatment of tuberculosis, Salmonella carriers, urinary tract infections and pathogenic studies in Gram-negative rod infections. (3) Studies of antibody responses, which included gonococcal and meningococcal infections, herpes simplex disease and staphylococcal states.
A series of papers on experimental infections covered: (1) Mycobacterium fortuitum in mice as a screen for tuberculosis; (2) hamycin in experimental mycoses in mice; (3) a standardized Leptospira pomona infection in hamsters; (4) experimental localized Pseudomonas infection (keratitis) in rabbits; (5) septicaemic anthrax in rhesus monkeys; (6) the use of sulphonamides in murine leprosy.

The modes of action of a number of antibiotics were mentioned, including $D$-cycloserine, vernamycin $A$, vancomycin, mitomycin $C$, porfiromycin and streptonigrin. Among the synthetic antimicrobial agents reported for the first time were an antifungal agent, tolnaftate $(O .2$. naphthyl- $m, N$-dimethylthiocarbanilate), 1-(5-nitrofurfurylideneamino)-2-imidazolidinone, and 4(5-nitro-2-furyl)-2-(3pyridyl)thiazole.

Most of the papers presented at the Conference will appear in Antimicrobial Agents and Chemotherapy, 1964, which will be published by the American Society for Microbiology (Ann Arbor, Michigan) in April 1965. The Proceedings will be distributed to all registrants at the meeting, and will be available from the American Society for Microbiology or from Messrs. H. K. Lewis, London.

Plans for the 1965 conference are already under way. This meeting will be combined with the fourth International Congress of Chemotherapy and will be jointly sponsored by the American Society for Microbiology and the International Society for Chemotherapy. Programmes on infectious diseases will be organized with the co-opera. tion of the Infectious Diseases Societ,y of America. The sessions will be held in the Shoreham Hotel, Washington, during October 17-2I. Dr. G. M. Savage (The Upjohn Co.) is general chairman, and enquiries concerning arrangements and participation should be sent to Mr. R. W. Sarber, Executive Secretary, American Society for Microbiology, 115 Huron View Boulevard, Ann Arbor, Michigan.
D. Perlman

\section{METEOROLOGY AND LOCUST MIGRATIONS}

$\mathrm{A}$

TECHNICAL Note recently published by the World Meteorological Organization covers a great deal of ground in the relationship between meteorology and the movement of locust populations*. Work on locust problems started in 1929 under Prof. B. P. Uvarov at what has now become the Anti-Locust Research Centre, and Dr. R. C. Rainey, who was a glider before the Second World War, a wartime meteorologist, and again an entomologist working with the Centre after the War, is uniquely qualified to write on meteorological aspects of locust populations. The note is very well produced, as are most of the World Meteorological Office Technical Note series, with 24 figures and three instructive photographs of locusts in flight, which hint at the problem - the immensity of which is realized by figures such as a swarm density per square kilometre of about $5 \times 10^{7}$ locusts, weighing $10^{5}$ kilograms and eating their own weight of vegetation each day. Swarms can cover hundreds or even thousands of square kilometres. As an example of financial loss, Morocco's loss in the year 1954-55 was assessed at about 13 million dollars; and Morocco was only one of 23 countries which suffered losses in that year.

The main emphasis is on the detailed survey for the year May 1954-May 1955, during which the Anti-Locust Research Centre collaborated closely with the World Meteorological Organization mission in East Africa headed

* World Meteorological Organization and Anti-Locust Research Centre. Meteorology and the Migration of Desert Locusts: Applications of Synoptic Meteorology in Locust Control. By R. C. Rainey. Pp. 115. (W.M.O. Technical Wote No. 54-No. 138. TP. 64. Anti-Locust Memoir No. 7.) (Geneva 1964.) $25 \mathrm{Sw}$. francs; 428 . by C. I. H. Aspliden, part author of Chapter 3. Considerable flying, both spotter and spraying, was undertaken, and swarm movements could be followed with far greater certainty than in any earlier work. Identifiable swarms flow for very variable distances up to $3,500 \mathrm{~km}$, with a maximum followed flight time of around two months. After a short introduction outlining the life cycle of the locust, meso-scale consideration is given to the individual swarm behaviour, and the general movement downwind is brought out clearly. Earlier investigations sometimes found variation between winds and swarm movements; this was presumably largely a question of difficultios of reliable assessment by ground observers, who could be unduly influenced by individual locust movements. Even in light winds, swarms nearly always moved more slowly than the surrounding air, although individual locusts may fly more quickly. 'This is caused by a sort of rolling effect, where the swarm 'front' rolls forward, with individual locusts spending some time on the ground if the swarm is low; flight level varied widely, however, with swarms at many thousands of feet on occasions. This agreement between wind and swarm movement is very valuable, as, for example, arrival of swarms in a new area can be foreseen.

The special survey year is documented with excellent monthly charts showing the locust distribution over the whole area from India westwards to Morocco, and includ. ing Central Africa; the development stage of the locust (whether hoppers, etc.) is also brought out. Each area is briefly discussed, with an analysis of locust behaviour during the year. 